\title{
Atypical Hemolytic Uremic Syndrome: New Challenges in the Complement Blockage Era
}

\author{
Ana Isabel Avila Bernabeu ${ }^{a} \quad$ Teresa Cavero Escribano $^{b} \quad$ Mercedes Cao Vilarino $^{c}$ \\ ${ }^{a}$ Department of Nephrology, Hospital Universitario Dr Peset, Valencia, Spain; ${ }^{b}$ Department of Nephrology, Hospital \\ Universitario Doce de Octubre, Madrid, Spain; 'Department of Nephrology, Hospital Universitario A Coruña, \\ A Coruña, Spain
}

\section{Keywords}

Atypical hemolytic uremic syndrome - Thrombotic microangiopathy · Complement · Eculizumab · Kidney transplant

\begin{abstract}
Atypical hemolytic uremic syndrome (aHUS) is a rare cause of thrombotic microangiopathy (TMA), characterized by microangiopathic hemolytic anemia, consumptive thrombocytopenia, and multisystem end organ involvement, most commonly affecting the kidney. Diagnosis is clinical, after exclusion of other TMA causes. Primary aHUS arises from genetic abnormalities, resulting in uncontrolled complement activity, while a variety of clinical scenarios cause secondary aHUS, including infection, pregnancy, malignancy, autoimmune disease, and medications. They can also induce a temporary complement deregulation with an overlap between both scenarios, which can make differential diagnosis difficult. Primary aHUS can be sporadic or familial and is associated with a high rate of progression to ESRD. Many aHUS patients relapse in the native or transplanted kidneys, leading to kidney failure. The introduction of eculizumab has changed the prognosis of aHUS, by inducing hematologic remission, improving or stabilizing kidney functions, and preventing graft failure. The early institution of appropriate
\end{abstract}

therapy can prevent multiorgan damage, so is essential to recognize and differentiate the TMA syndromes. Eculizumab is considered now the first-line treatment, and it is recommended lifelong therapy. However, the high cost of therapy has led to make efforts to develop precise complement functional and genetic studies that help physicians to determine the appropriate duration of eculizumab therapy. Nowadays, more studies are needed to select candidates to adjustment of therapy.

(c) 2020 S. Karger AG, Basel

\section{Introduction}

Hemolytic uremic syndrome (HUS) is one of the disorders that belong to the spectrum of the thrombotic microangiopathy (TMA). TMAs are a group of life-threatening diseases, characterized by endothelial dysfunction and the presence of thrombi in small blood vessels. As the thrombus forms, there is consumption of platelets and mechanical disruption of erythrocytes, which leads to thrombocytopenia and microangiopathic hemolytic anemia. Vessel occlusion results in tissue ischemia and organ damage, mainly affecting the kidneys although other organs can be involved [1-4].

$\begin{aligned} & \text { karger@karger.com } \\ & \text { www.karger.com/nef }\end{aligned}$
Karger ${ }^{\prime /}$

Ana Isabel Avila Bernabeu

Department of Nephrology, Hospital Universitario Dr Peset Avda Gaspar Aguilar, 90 ES-46017 Valencia (Spain) aaaavilab@gmail.com 


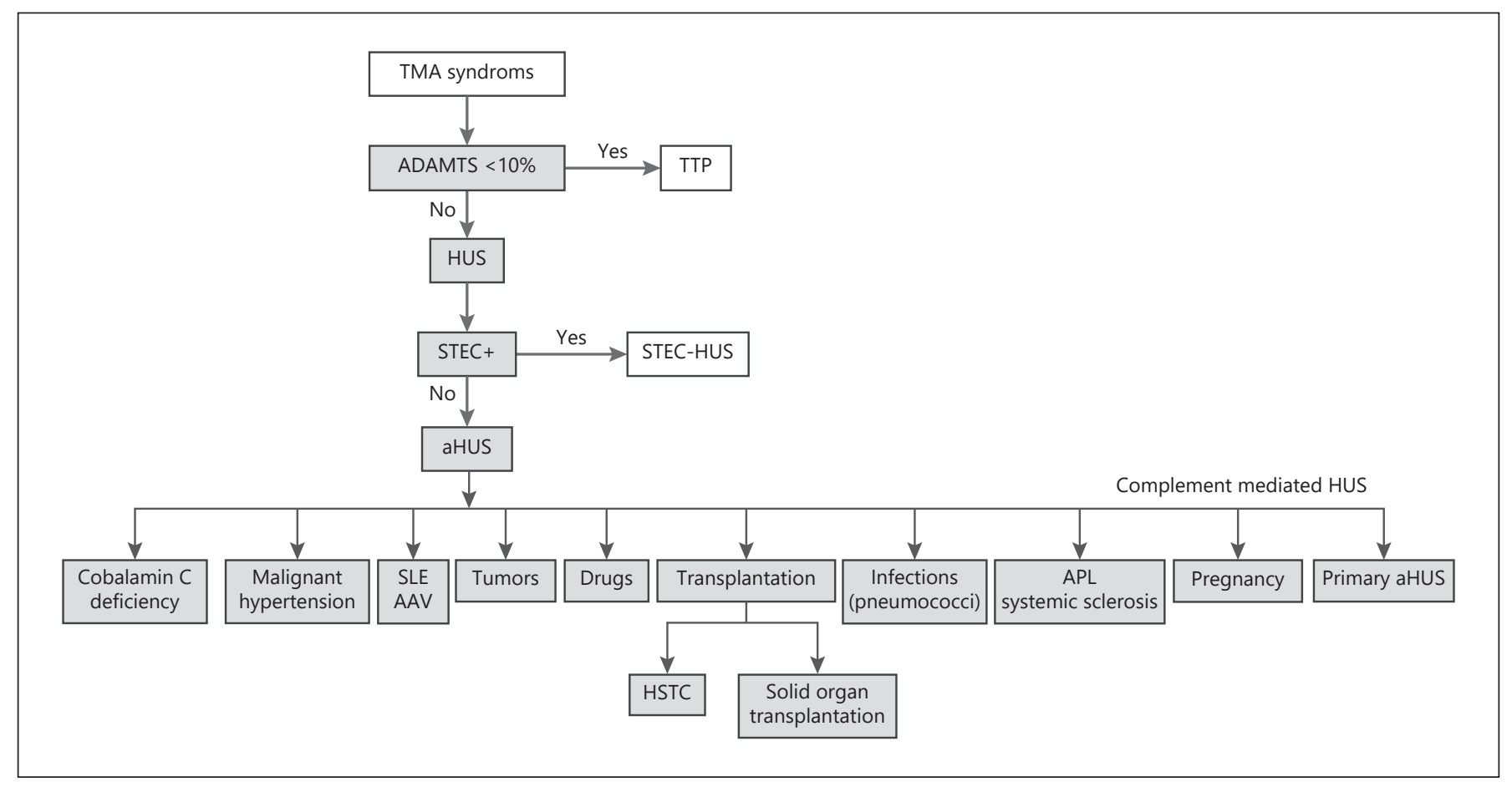

Fig. 1. TMAs classification. TMA, thrombotic microangiopathy; HUS, hemolytic uremic syndrome; STEC, shiga toxin associated; SLE, systemic lupus erythematosus; AAV, ANCA-associated vasculitis; HSCT, hematopoietic stem cell transplantation; APL, antiphospholipid syndrome. Classification of TMA syndromes. Primary TMA syndromes include TTP, STEC-HUS, and primary aHUS. aHUS is diagnosed after ruling out TTP (ADAMTS13 ac-

TMAs can be categorized as primary or secondary, according to the pathogenetic mechanism (Fig. 1). Primary TMA syndromes comprise thrombotic thrombocytopenic purpura (TTP), HUS caused by shiga toxin-producing Escherichia coli (STEC-HUS, also named typical HUS), and atypical HUS (aHUS) [5, 6], caused by inherited and/ or acquired abnormalities in complement proteins driving to unregulated activation of the alternative pathway (AP) and the formation of the membrane attack complex (MAC) [1]. The most common form of primary TMA in children is STEC-HUS, while in adults, it is TTP. The secondary TMAs are related to infections (Streptococcus pneumoniae and human immunodeficiency virus), malignancies, drugs (cancer chemotherapy, calcineurin inhibitors [CNIs], and mammalian target of rapamycin inhibitors), autoimmune diseases (systemic lupus erythematosus and vasculitis), organ transplantation (solid organ and hematopoietic stem cell transplantation), or metabolic disease (cobalamin C [cblC] deficiency) $[3,7]$. TMAs are also part of other conditions such as HELLP syndrome, tivity $>10 \%$ ) and STEC-HUS. aHUS can be due to cobalamin C deficiency, a congenital vitamin B metabolism disease, or due to complement mediated HUS. The latter will be primary in the setting of genetic variants of the complement proteins or secondary to temporary complement deregulation in different diseases. There is some overlap between primary and secondary aHUS.

disseminated intravascular coagulation, antiphospholipid antibody syndrome, and scleroderma renal crisis [5]. The relationship between malignant hypertension and TMA has been discussed [51]. Secondary TMAs are also called secondary aHUS, as a complement deregulation has been described in some of those conditions [5]. In spite of the differentiation between primary and secondary aHUS, the classification remains controversial as there is overlap between these categories.

aHUS is an ultra-rare disease with an estimated incidence between 0.5 and 2 patients per million [8-11]. aHUS occurs at any age, from the neonatal period to the adult age. It accounts for $11 \%$ of HUS in children [8]. Onset during childhood ( $\leq 18$ years) appears slightly less frequent than during adulthood (approximately 40 and $60 \%$, respectively) [12]. It is almost equally frequent in boys and girls when onset occurs during childhood (1.3:1) [11], but in adults, there is a female preponderance $(2: 1)$. Sixteen percent of cases are familial forms [12]. Median age at presentation is 21 years ( 10 years in males and 25 


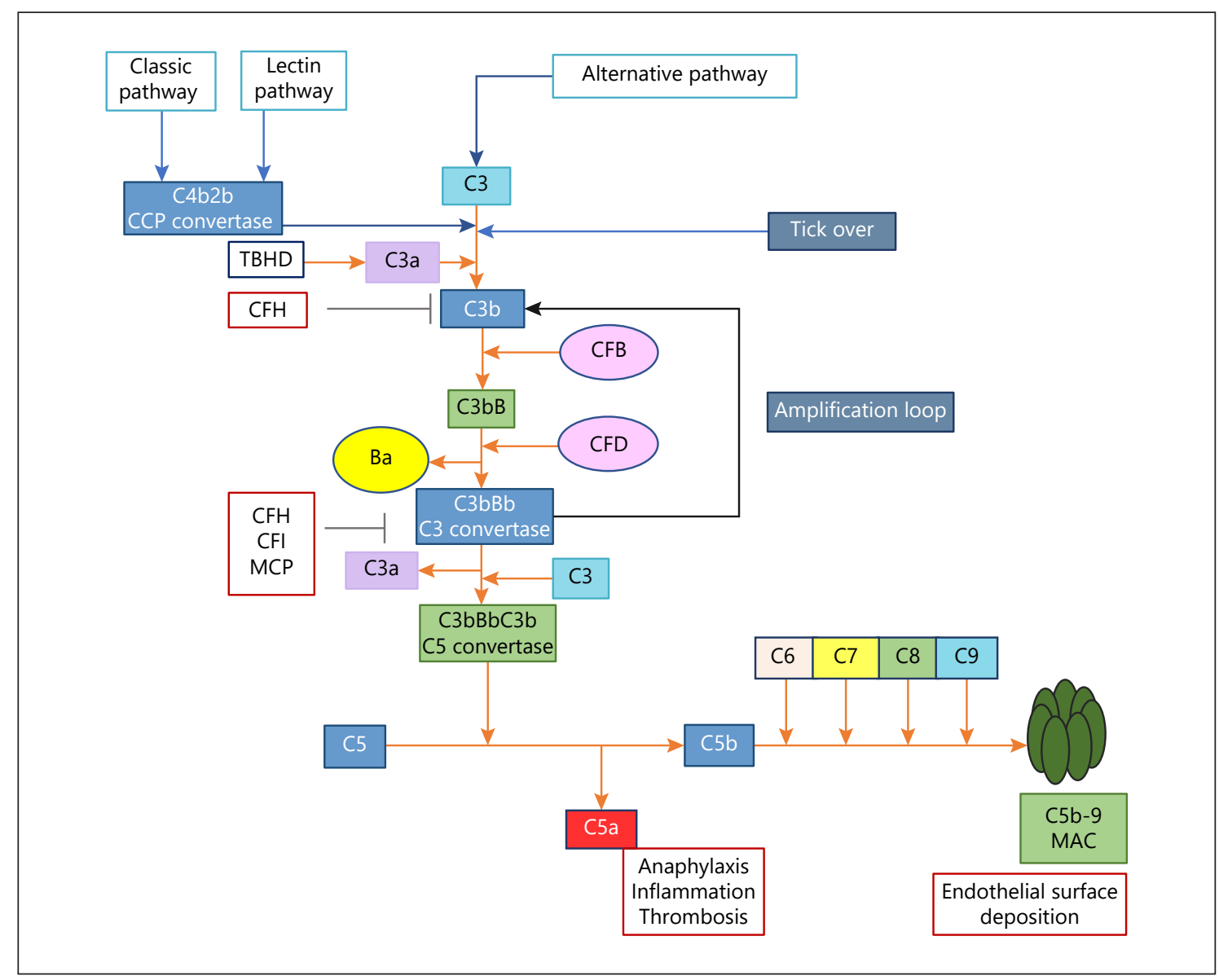

Fig. 2. Activation of the complement system. CCP, classical complement pathway; $\mathrm{C} 3 \mathrm{~b}$, activated $\mathrm{C} 3$; $\mathrm{CFB}$, complement factor $\mathrm{B}$; CFD, complement factor D; C3bBb, C3 convertase; C3bBbC3b, C5 convertase; $\mathrm{CFH}$, complement factor $\mathrm{H}$; CFI, complement factor I; MCP, membrane cofactor protein; TBHD, thrombomodulin; MAC, membrane attack complex; AP, alternative pathway. Initiation of complement cascade begins with activation of C3. AP is "always on," and it remains activated via the tick-over process and formation of $\mathrm{C} 3 \mathrm{bBb}$ ( $\mathrm{C} 3$ convertase). $\mathrm{C} 3$ convertase hydrolyzes $\mathrm{C} 3$

in females). Onset before 6 months of age is highly indicative of aHUS (being STEC-HUS uncommon in this group). The onset is usually triggered by a febrile infection in the respiratory or gastrointestinal tract [13].

\section{Pathogenesis of Complement-Mediated aHUS}

The complement system is an essential part of innate immunity and is activated via 3 pathways: classical pathway, lectin pathway, and AP. Activation of any of these pathways eventually leads to the opsonization of pathogens and the generation of anaphylatoxins (C3a and C5a) into C3a and C3b. The latter joins to cell surfaces and CFB. CFD cleaves $\mathrm{CFB}$ into $\mathrm{Ba}$ and $\mathrm{Bb}$. $\mathrm{C} 3 \mathrm{~b}$ joins $\mathrm{Bb}$, resulting in $\mathrm{C} 3 \mathrm{bBb}$ on cell surface. The addition of $\mathrm{C} 3 \mathrm{~b}$ to $\mathrm{C} 3 \mathrm{bBb}$ originates $\mathrm{C} 3 \mathrm{bBbC} 3 \mathrm{~b}$ (C5 convertase), leading to the formation of C5b-9 or MAC. C3 convertase is stabilized by properdin protein and is cleaved by $\mathrm{CFH}$ and CR1. CRPs (CFH, CFI, and MCP) modulate the "tickover" process of AP activation and protect host cells from activated complement proteins generated via all 3 pathways.

and MAC. The activation of both classical and lectin pathways needs specific initiator, but the AP is "always on" at low level by the hydrolysis of complement factor C3. It allows the constant formation of a C3 convertase (called "tick-over"), ensuing a rapid response to pathogens (Fig. 2). C3 convertase facilitates formation of C5b-9 (MAC) that forms a transmembrane channel, causing cell lysis [14]. The complement system is exquisitely controlled by the complement regulatory proteins (CRPs): complement factor $\mathrm{H}(\mathrm{CFH})$, complement factor I (CFI), and membrane cofactor protein (MCP or CD46). CRPs modulate the "always on" feature of the AP to ensure that once the complement cascade is amplified, the end prod- 
Table 1. Mechanism of induce TMA; Mechanisms that explain the development of secondary aHUS

Cancer-associated Complement proteins are critical for the development of cancer neovascularization by altering endothelial cell function and TMA $[40,41,54]$ VEGF expression. Thrombin generation can activate the complement system

Drug-related TMA Direct toxic effect on endothelium, antibodies to VEGF, or immune complex-mediated damage to endothelium. Deficiency [41] of prostacyclin would promote platelet aggregation and vascular constriction. Levels of plasma thrombomodulin, a sign of endothelial activation, along with tissue plasminogen activator and plasminogen activator inhibitor-1, are increased

TMA occurred more often with VEGF-ligand inhibitors than with tyrosine kinase inhibitors, which more often caused damage to the podocytes

Direct dose-dependent endothelial cell toxicity with gemcitabine and mitomycin C

Pregnancy

$[42,52,53]$

Diagnosis most often occurred postpartum (94\%), after a cesarean delivery (70\%). Abnormalities in complement genes are relatively common. Eculizumab could be an effective treatment

The onset of TMA in preeclampsia and HELLP syndrome occurs during pregnancy and improves after delivery, while P-aHUS develops in up to 70-75\% of cases postpartum and in case of prepartum, aHUS does not improve after delivery

Solid organ In kidney transplantation rule out primary aHUS if unknown cause of CKD. CNI and mTOR inhibitor toxicity, antibodytransplantation [87] mediated acute rejection, and infections could trigger TMA

Hematopoietic stem Severe multivisceral TMA associated with a high mortality (>80\%). Multifactorial endothelial cell damage: chemotherapy, cell transplantation [43] total body irradiation, CNI toxicity, graft versus host disease, and infections

Autoimmune diseases $[44,45]$
Systemic lupus erythematosus: endothelial cell injury mediated by immune complexes. Formation of the MAC through the classical complement pathway

Antiphospholipid syndrome: two-hit hypothesis: First hit: binding of anti-b2GPI antibodies to their target on endothelial cells leads to the upregulation of adhesion molecules and tissue factor. Second hit: inflammatory trigger and activation of the complement cascade lead to thrombosis

Systemic sclerosis: vessel wall intimal proliferation and lumen obstruction

Infections [46-49]

HIV, CMV, HHV6, and parvovirus: potential direct viral endothelial cell toxicity
H1N1: unmasking of T-F antigen on red blood cells and endothelial cells has been suggested (see Streptococcus pneumoniae below)

S. pneumoniae: neuraminidase cleaves sialic acid residues off of endothelial cell receptor glycoproteins and exposes the T-F antigen. IgM anti-T antibodies bind to newly exposed T-antigen and damage endothelial cell. S. pneumoniae activates human plasminogen that degrades fibrinogen and cleaves C3b, mediating endothelial cell injury

Coexisting nephropathies [50]
IgA nephropathy, C3 glomerulopathy, or other membranoproliferative glomerulonephritis, ANCA, or anti-GBM vasculitis could be complicated with TMA

TMA, thrombotic microangiopathy; VEGF, vascular endothelial growth factor; HELLP, hemolysis, elevated liver enzymes, low platelets; P-aHUS, pregnancy-associated atypical hemolytic uremic syndrome; CNI, calcineurin inhibitors; mTOR, mammalian target of rapamycin; CMV, cytomegalovirus; HIV, human immunodeficiency virus; HHV6, human herpes virus 6; H1N1, influenza A virus subtype H1N1; MAC, membrane attack complex; T-F antigen, Thomsen-Friedenreich antigen.

ucts (C5a and C5b-9) action is limited to pathogens, protecting host cells. An inherited (primary aHUS) or acquired (secondary aHUS) deregulation of the alternative complement pathway will lead to an impaired protection of endothelial cell surfaces, allowing the abnormal formation of the MAC on the surface of the endothelial cells (Table 1). This fact will lead to endothelial cell apoptosis and TMA, often with a predilection for the renal vasculature [15]. MAC induces endothelial cell lesion also in STEC- [16] and S. pneumoniae-induced HUS [17], in some secondary aHUS, and, of course, in primary genetic aHUS. However, the ultimate mechanism underlying some forms of HUS such as DGKE or THBD gene variants and cblC deficiency or even in secondary aHUS is still unknown, despite the fact that complement dysregulation has been shown in the majority of these settings [3].

\section{Genetics of aHUS}

Genetic variants in CRPs account for $50-60 \%$ of aHUS cases $[10,19]$. In $9 / 10$ cases, they are heterozygous variants. They can cause deficit (type I) or altered function (type II) of the protein [19]. In $40-50 \%$ of cases, mutations are not 
Table 2. Frequency of genetic variants in complement regulatory factors, according to geographic location

\begin{tabular}{|c|c|c|c|c|}
\hline $\mathrm{CFH}, \%$ & 24 & $20-30$ & 10 & 27 \\
\hline CFI, \% & 4 & $4-10$ & - & 8 \\
\hline MCP, \% & 7 & $5-15$ & 5 & 5 \\
\hline $\mathrm{C} 3, \%$ & 4 & $2-10$ & 31 & 2 \\
\hline Combined, \% & 3 & 2 & 5 & \\
\hline Anti-FH antibodies, \% & - & $6-10$ & 19 & \\
\hline
\end{tabular}

$\mathrm{CFH}$, complement factor $\mathrm{H}$; CFI, complement factor I; CFB, complement factor B; MCP, membrane cofactor protein; TBHD, thrombomodulin.

detected, but it does not exclude AP deregulation. CRPs may be impaired in their action by loss-of-function mutations (CFH [20], CFI [21], MCP [22], and thrombomodulin [THBD]) [23], acquired antibodies anti-CFH [26], or CFH/CFHR rearrangements caused by genomic duplications [27]. Conversely, gain-of-function mutations in CFB [24] or C3 [25] lead to increased activity, surpassing the capacity of controlling the complement activation. Pathogenic variants in vitronectin, a terminal pathway inhibitor has also been described [29], as well as variants not related to the complement system, such as diacylglycerol kinase $\varepsilon$ (an endothelial cell and podocyte protein whose genetic deficiency causes aHUS in children) [30,31]. The frequency of the variants shows geographical differences (Table 2) $[32,33]$. A polymorphism in C5 (c2654 G > A;pArg) was detected in Japanese patients, who showed poor response to eculizumab [34], with no cases reported so far in other populations. Some patients carry hybrid genes or rearrangement $\mathrm{CFH}$-related proteins (CFHR1-5), being the resultant proteins antagonistic to $\mathrm{CFH}$ [35]. The penetrance of the disease is low, as less than half of family members carrying the same mutation develop aHUS $[10,19]$. It increases up to $70 \%$ with age, combined mutations (3-10\% of patients) [36], risk polymorphisms in MCP (ggaac) or $\mathrm{CFH}$ (H3) [20], or a strong complement activating condition. The role of the risk polymorphisms in the development of the disease in patients without other complement proteins pathogenic variants is not clear as they are frequent in general population, so it is doubtful that by themselves unleash the disease [69]. Anti-CFH antibodies aHUS is not strictly an acquired form, as they are associated with CFHR3-1 homozygous deletion in $90 \%$ of cases. This form is more frequent in pediatric $(25-50 \%)$ than in adult patients $(5-10 \%)[27,28]$.

aHUS: New Challenges

\section{Diagnosis and Differential Diagnosis of aHUS}

The main target in TMA is the endothelial cell. Although TMA is a histological definition, based on the occurrence of intraluminal fibrin and platelet thrombi in small vessels, endothelial cell detachment, and widening of the subendothelial space, the diagnosis is usually clinical and made by default. The presence of microangiopathic hemolytic anemia with low hemoglobin, elevated lactate dehydrogenase (LDH), descended haptoglobin, thrombocytopenia, and schistocytes in blood smear with clinical or analytical data of organ ischemia such as increased serum creatinine, oliguria, neurological symptoms, heart failure, and so forth, should make us suspect TMA. Only eventually histological confirmation is necessary $[5,6,18]$.

The complete TMA picture is sometimes absent, hindering the diagnosis. Up to $20 \%$ of the patients with aHUS do not have thrombocytopenia, and in this setting, $\mathrm{LDH}$ should be normal. The presence of schistocytes is variable, and TMA could be subacute or chronic and even more it has been described the "cryptical activity of aHUS," characterized by proteinuria or unexplained anemia as unique signs in the absence of other signs of TMA [37-39].

Differential diagnosis includes several pathologies that can be grouped according to TMA trigger (Fig. 3) [4056]. TTP arises from an acquired or congenital severe deficiency of a disintegrin-like and metalloproteinase with thrombospondin type 1 motif, 13 (ADAMTS13), a specific cleaving protease of von Willebrand factor (VWF). Ultra-large VWF multimers due to the lack of $\mathrm{AD}$ AMTS13 activity promote the formation of microvascular platelet thrombi in small vessels $[4,19]$. TTP usually 


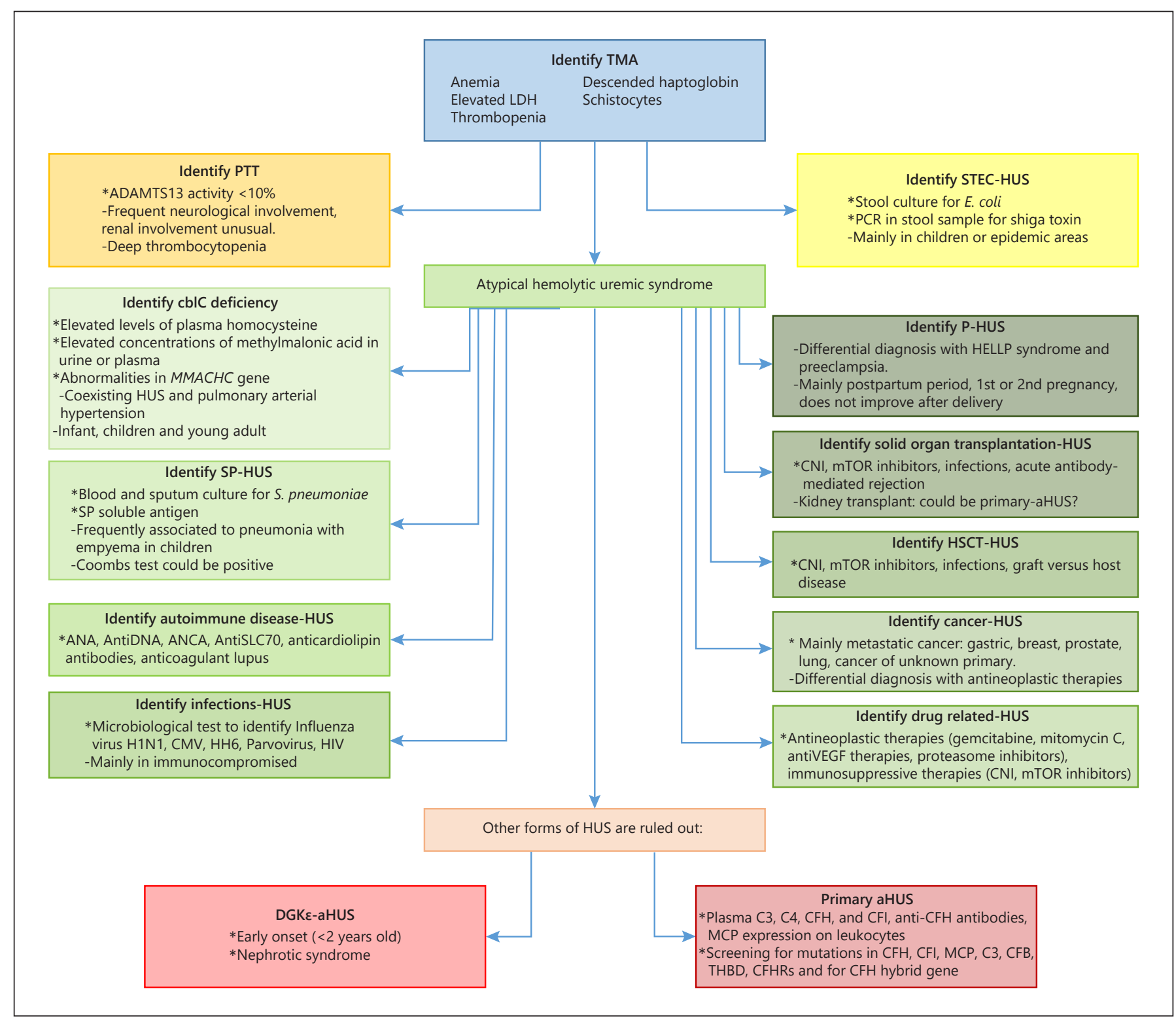

Fig. 3. Differential diagnosis of TMA syndromes. ANA, antinuclear antibodies; ANCA, anti-neutrophil cytoplasmic antibody; CFB, complement factor B; CFH, complement factor H; CFHRs, complement factor $\mathrm{H}$ related; CFI, complement factor I; CMV, cytomegalovirus; CNI, calcineurin inhibitors; $D G K \varepsilon$, diacylglycerol kinase epsilon; HIV, human immunodeficiency virus; HELLP, hemolysis, elevated liver enzymes, low platelet; HHV6, human herpes virus 6; HSCT, hematopoietic stem cell transplantation; HUS, hemolytic uremic syndrome; $\mathrm{H} 1 \mathrm{~N} 1$, influenza virus subtype $\mathrm{H} 1 \mathrm{~N} 1$;

presents with neurological signs, being renal involvement unusual. Therefore, the determination of the activity of ADAMTS13 is always included in the diagnostic algorithms of TMA [3]. Typical HUS is associated with STEC or other enteropathogenic bacteria. Shiga toxin binds to
LDH, lactate dehydrogenase; MCP, membrane cofactor protein; $M M A C H C$, methylmalonic aciduria and homocystinuria type C; mTOR, mammalian target of rapamycin; P-HUS, pregnancy-associated hemolytic uremic syndrome; SP-HUS, Streptococcus pneumoniae-associated hemolytic uremic syndrome; STEC, shiga toxin-producing E. coli; THBD, thrombomodulin; TMA, thrombotic microangiopathy; VEGF, vascular endothelial growth factor. Main characteristics from each atypical HUS, either primary or secondary, to other conditions.

globotriaosylceramide on target cell surface and leads to cytotoxicity, inducing the secretion of large VWF multimers from endothelial cells. STEC-HUS should be ruled out in patients with TMA presenting with diarrhea, mainly in children and epidemic areas [16]. But the main dif- 
ferential diagnosis of aHUS arises between primary and secondary forms.

Clinical features and additional investigations are usually needed to differentiate both forms. S. pneumoniaeinduced HUS occurs more frequently in children and usually associated with pneumonia with empyema and/ or meningitis [55]. Pregnancy-associated HUS (P-HUS) develops in postpartum period $(73-79 \%)[42,52,53]$ although its appearance during pregnancy is feasible. Cancer-related HUS is associated with metastatic cancer in up to $90 \%$ of cases [40,41], being able to relapse after complete remission with cancer recurrence. Lots of drugs have been associated with HUS, mainly drugs used in immunosuppressive therapy - solid organ transplant or hematopoietic stem cell transplantation - or antineoplastic therapies - gemcitabine, cisplatin, anti-VEGF therapy, proteasome inhibitors, and so forth [41]. Presence of TMA and pulmonary arterial hypertension in infants but also in older children or young adults should make us suspect a cblC deficiency [56].

When secondary causes of HUS have been discarded, complement and DGKE investigations will be done. Normal level of plasma complement proteins or negative genetic study does not rule out primary aHUS. Low C3 level is only present in $30 \%$ of cases [10]. The demonstration of complement activation (measuring C5b-9 deposition on unactivated endothelial cells) after exposure to aHUS patient's serum can be useful for the diagnosis of aHUS, but it is not widely available [67]. Therefore, we currently do not have any biomarker or diagnostic test to distinguish accurately between primary and secondary aHUS. This differential diagnosis must be done in few hours or days in order to not delay treatment of aHUS.

\section{Treatment of aHUS}

Historically, plasma infusion or plasma exchange (PI/ $\mathrm{PE})$ was the standard of care by supplying the functional complement inhibitory molecules. But the outcomes of patients treated with PI/PE remained unsatisfactory as nearly $70 \%$ of patients with complement genetic variants died or reached ESRD during the first episode of aHUS or within 3 years $[10,18,22]$. The outcomes of PI/PE varied depending on the underlying genetic variants. Patients with $\mathrm{CFH}$ had a greater likelihood of developing ESRD and post-transplant recurrence, while carriers of variants in MCP had a better prognosis despite multiple relapses. PI/PE is not exempt from adverse effects as hypotension, hypocalcemia, and catheter complications
[57]. Nevertheless, PI/PE is still used until TTP is discarded, when eculizumab is not available and in anti-CFH antibodies aHUS $[2,58]$. Liver transplantation has been proposed for aHUS caused by genetic variants in complement proteins synthesized in the liver (CFH, CFI, FB, and C3), mainly if the patient needs also a kidney transplant. This technique showed at first a high morbidity and mortality, but the use of PI/PE or eculizumab until liver function is adequate is surely justifiable and may be worthwhile since liver transplantation corrects the genetic defect forever $[59,60]$. In any case, this type of transplant should only be performed in centers with proven expertise, after a careful balance of risks/benefits and against the alternative of eculizumab, currently considered the "gold standard" of treatment [61].

Eculizumab, a humanized monoclonal antibody, inhibits the terminal complement activity. It joins C5 and prevents its cleavage, inhibiting the formation of MAC. It has a high efficacy in avoiding complement-mediated cell injury in TMA [62]. The first clinical trials performed to analyze the efficacy of eculizumab showed a high efficacy in inducing hematologic remission and improving kidney function in patients with aHUS $[62,63]$. The first trial showed a TMA response in $65 \%$ at 26 weeks, rising to $95 \%$ at 2 years (length of the extension trial). Almost $50 \%$ of patients after 1 week and up to $90 \%$ at 26 weeks had normalized platelet count, and the remaining were normal during all the study period. LDH was normalized in $90 \%$. eGFR improved in 76 and $80 \%$ of patients who were withdrawn from dialysis at 26 weeks. In the second trial, performed in patients with persistent kidney damage despite $\mathrm{PI} / \mathrm{PE}$, after eculizumab introduction, $95 \%$ of patients were free of TMA events at the end of the study, stopping $\mathrm{PI} / \mathrm{PE}$ and dialysis and improving kidney function in $40 \%$ of patients. Quality of life improved in more than $70 \%$ of patients in both trials. Those results were confirmed in some studies performed in children and in adults $[19,64,65]$, making nowadays eculizumab the first-line therapy in children with aHUS [24] and in adults after exclusion of other causes of TMA [6]. Eculizumab is more effective the earlier the onset of treatment after diagnosis [66]. Early initiation of eculizumab is associated with better treatment outcomes and greater improvements in eGFR. Renal prognosis relies on the treatment precocity, independent of the genetic variant. Eculizum$a b$ treatment is equally effective in all genetic variants and also in patients without identified variants.

It is unclear from what moment eculizumab has no beneficial effect on kidney function, since patients who have been on dialysis for a long time (including years) and 
recovered kidney function after starting eculizumab treatment have been described [68-71]. The mechanism by which eculizumab leads to late recovery is not well understood, although it can be explained by slow dissolution of thrombi with recanalization of the glomerular capillaries, besides the control of endothelial injury halted by eculizumab. To evaluate the complement blockage potential benefit in patients with established renal damage, a kidney biopsy can be useful. The degree of vascular damage and the presence of cortical necrosis correlate with poor outcomes. The findings of active TMA changes may suggest the possibility of improvement with treatment [72].

The optimal duration of eculizumab therapy in aHUS has not yet been determined. The potential risk of developing TMA following discontinuation of treatment [73, 76] and the recommendation of lifelong treatment have been noted in regulatory guidance. But several issues such as the risk of meningococcal meningitis and the high cost of therapy have led to discontinuation of treatment being attempted. Although the data supporting eculizumab cessation are limited to small cohort studies and case reports, recommendations for considering eculizumab cessation emphasize on a case by case analysis only in patients who have received at least 6-12 months of treatment and have a normal renal function $[5,18]$. The overall risk of TMA relapse in patients with prolonged treatment with eculizumab (0.5-17 months) is $25-30 \%$ [ 73,76$]$, but one of the drawbacks of these studies is the small duration of followup, being necessary to look for the long-term outcomes after discontinuation. In the published studies, the risk of TMA relapse depends largely on the underlying genetic variant [19]. Fakhouri and colleagues showed a low risk of recurrent TMA in patients without genetic variants. However, the risk is high in patients with $\mathrm{CFH}$ variants, followed by MCP and by far by CFI variants [74-77]. Following drug withdrawal, patients should be monitored for signs and symptoms of TMA complications. After a TMA relapse, a rapid reintroduction of eculizumab can lead to a rapid remission. Discontinuation is not recommended by now in renal transplant recipients, patients with recurrent relapses, and children until they are 3-5 years old $[5,16,18,73]$. Eculizumab administration consists of one $900 \mathrm{mg}$ weekly dose for 4 weeks, followed by twice-weekly 1,200 mg maintenance dose. The dosing is weight based for patients aged 18 years or younger, and a fixed dose for adults weighing more than $40 \mathrm{~kg}$. But the fixed dose (or intervals) can be questioned and monitoring the degree of complement blockade with eculizumab can be useful in an attempt to individualize treatment. The classical clinical markers (hemoglobin, platelets,
$\mathrm{LDH}$, and haptoglobin) have a limited utility to guide eculizumab dosage, as they are rough markers of complement blockade. Complement protein levels (C3 and C5) and functional activity of complement regulators neither are useful $[78,79]$. Total complement activity $(\mathrm{CH} 50)$ and alternative pathway complement activity (AH50) are the most commonly used tests to assess the complement activity [73]. Treatment with eculizumab reduces $\mathrm{CH} 50$ activity below $<10 \%$ (expected response). $\mathrm{CH} 50$ assay is widely available, but it has serious disadvantages as the high diversity between the different tests and a trend to the variability of $\mathrm{CH} 50$ in the low range, which limit its clinical utility. The AH50 lacks specificity. They do not efficiently detect relapse during eculizumab dosage tapering/treatment discontinuation [67]. Wieslab Complement screen assay measures the degree of activity of classical pathway and AP using a specific antibody against a neoantigen expressed during the formation of C5b-9. It is more sensitive than $\mathrm{CH} 50$ to detect complement activity in low range [81]. As for the usefulness of plasma sC5b-9, data available so far are controversial and its utility is questioned. Abnormal activation of complement leads to elevated levels of sC5b-C9 and the levels should decrease during treatment, but different studies show variable results $[67,79,81]$. More studies are needed to evaluate its use in adjusting treatment dose. Regarding eculizumab $C_{\text {trough }}$ levels, the dose was designed to reach plasmatic levels 50-100 ng/mL, keeping free C5 low and suppressing C5 cleavage [11]. In most studies, to individualize eculizumab dosage, a measure of the complement blockade (CH50, Wieslab, C5 activity) combined with monitoring eculizumab (by $C_{\text {trough }}$ levels or measuring the free C5) is used [80-82]. $C_{\text {trough }}$ levels $>50 \mu \mathrm{g} / \mathrm{mL}$ correlated with a decrease in free C5 by $>90 \%$ [77]. Many small cohort studies have showed adequate complement blockade while increasing the maintenance dosing intervals to more than 2 weeks. Cugno et al. [78] increased dosing interval to every 3 or even 4 weeks, measuring complement activity regularly. Gatault et al. [80] increased interval according to patient's weight, while maintained appropriate eculizumab levels. Wijnsma et al. [77] used $C_{\text {trough }}$ level associated with C5 inhibition to individualize eculizumab therapy. When $C_{\text {trough }}$ levels were below $30 \mu \mathrm{g} / \mathrm{mL}$, the dosing interval was decreased to 1 week. Between 30 and $90 \mu \mathrm{g} / \mathrm{mL}$, the 2-week interval was maintained. From 90 to $120 \mu \mathrm{g} / \mathrm{mL}$ resulted in a 3-week; from 120 to $210 \mu \mathrm{g} / \mathrm{mL}$, in a 4 -week; and $>210 \mu \mathrm{g} / \mathrm{mL}$, 5-week dosing intervals. Ardissino et al. [74] evaluated aHUS patients treated with eculizumab at extended intervals (every 3 or 4 weeks) during the maintenance phase. 
Maintaining the classical complement pathway activity of $<30 \%$, no relapses were noticed after a prolonged observation period. But in all these studies the behavior of the complement in plasma was observed, which does not accurately reflect complement activity on endothelial cells, so the most reliable test to date to predict TMA relapse during tapering/discontinuation is the measurement of C5b-9 deposition on unactivated endothelial cells after exposure to aHUS patient's serum. Eculizumab blocked this deposit, and its detection enables to evaluate the degree of complement blockade after dose modifications, allowing the dose individualization without TMA relapses [67]. Monitoring complement blockade can be used to individualize eculizumab treatment, reducing the burden of the therapy without increasing the risk of a TMA relapse according to small case series. But for now, the most specific tests to measure complement blockade are available only in limited laboratories, so it is needed to be cautious when discontinuation is performed and ensure the prompt recognition of a relapse in order to adjust eculizumab treatment to prevent organ damage.

The development of new drugs that interfere at various stages of the complement pathway is being performed. CCX168, an orally administered C5aR antagonist; ravulizumab, a C5-binding antibody, which releases $\mathrm{C} 5$ at low $\mathrm{pH}$; the lectin pathway inhibitor OMS721, which binds and blocks MASP2 action; coversin, a C5 inhibitor derived from the tick (Ornithodoros moubata); and many other agents will impact the aHUS treatment in the future $[97,99]$.

\section{Kidney Transplant}

The occurrence of de novo aHUS after kidney transplant is an uncommon complication, observed in $0.8-15 \%$ of kidney transplants and results in graft loss in up to $1 / 3$ of them $[83,84]$. Several issues in this context are challenging. First of all, the differential diagnosis between de novo post-transplant aHUS (PT-aHUS) and primary aHUS recurrence. Different factors concur that can provoke the former or trigger the latter, activating complement cascade [85]. Expanded criteria donors, brain death, ischemia-reperfusion injury, vascular surgery, the use of immunosuppressive drugs such as CNIs, cyclosporine or tacrolimus, or mammalian target of rapamycin inhibitors, sirolimus or everolimus; infections; and acute rejection act activate complement cascade [86-89]. Clinical and microscopic characteristics of PT-aHUS are indistinguishable from those of recurrent aHUS. Furthermore, genetic variants of complement proteins are observed in up to $30 \%$ of patients with PT-aHUS $[83,84]$. Personal and family histories, abrupt onset, and accentuated systemic and hematologic involvement are more common in recurrent aHUS, but they do not exclude PT-aHUS [6]. Prognosis of renal transplantation in patients with primary aHUS prior to eculizumab approval was dramatic because of graft thrombosis and disease recurrence, usually early and conditioning a high rate of graft loss [92]. Recurrence rate reached $80-100 \%$ in the presence of mutations in $\mathrm{FH}$ or FI. Those patients were mostly excluded not only from the cadaveric donor transplant waiting list but also from the living donor transplant $[90,91]$. Eculizumab changed dramatically this scene, allowing renal transplantation in aHUS patients [90]. The stratification of the recurrence risk has been very useful in the management of the disease [5]. High recurrence risk is considered in patients with recurrence in previous transplants and carriers of pathogenic variants in $\mathrm{CFH} / \mathrm{CFB} / \mathrm{C} 3 / \mathrm{FH}$ :FHR1 rearrangements; moderate risk in carriers of CFI variants/anti-FH antibodies/homozygous for haplotypes CFH-H3/absence of variants; and low risk in isolated MCP/TBHD/DGKE variants and negative anti-FH antibodies at the time of transplantation. The use of eculizumab prophylaxis versus no prophylaxis in transplanted aHUS patients was analyzed by Zuber et al. [90]. They compared the risk of recurrence in 116 patients. Eculizumab prophylaxis group had a higher frequency of complement/DGKE abnormalities, a higher proportion of high relapse risk, and a lower frequency of expanded criteria donors. Clinical and subclinical recurrence occurred in 40.5 and $12.1 \%$, respectively, of the transplantations without prophylaxis, and in $3 \%$ of patients with prophylaxis.

When eculizumab was used to treat recurrence, graft survival improved compared to patients treated with $\mathrm{PE}$, even if its use was delayed $>7$ days. However, graft survival was worse than with prophylactic therapy. The use of eculizumab in transplantation has also increased the number of patients who received a transplant between 2012 and 2016 from 46.2 to $72.3 \%$; On the other hand, while $60 \%$ of patients carrying variants in $\mathrm{CFH}$ remained on dialysis until 2012 , only $27 \%$ did so in 2016 , thanks to the possibility of a successful transplant. A high index of suspicion, prompt diagnosis, and utilization of eculizum$\mathrm{ab}$ are key to successful salvage of allografts in cases of aHUS after kidney transplantation [98].

The interruption of treatment in kidney transplantation poses technical and ethical problems [76, 93]. Preliminary data suggest that genetic background may be decisive for relapse after drug discontinuation. A French 
group [94] reviewed its experience after the interruption of eculizumab in living donor transplants. It was performed more frequently in patients at moderate than at high risk, 53.9 versus $13.5 \%$. There was 1 relapse in the high-risk but none in the moderate-risk group. Given the short follow-up time, when late relapses are described, one must be cautious when recommending withdrawal.

A Dutch group has performed living donor kidney transplants in patients with aHUS using CNI minimization, administration of basiliximab, measures to minimize endothelial damage, and very strict clinical monitoring, without prophylactic administration of eculizumab. The evolution has been good, although 6 of the 17 patients had received a previous kidney transplant and 5 out of 6 lost their grafts due to aHUS recurrence $[95,96]$. A Bergamo group has also reported a successful experience of cadaveric donor transplantation in recipients treated with basiliximab [97].

\section{Conclusion}

The recognition and differential diagnosis of primary aHUS can be challenging as there are situations that cause complement activation, mimicking aHUS (secondary aHUS). Establishing a rapid diagnosis is crucial in order to start rapid treatment to minimize organ damage. Eculizumab, a monoclonal antibody against complement C5, has dramatically improved the evolution in aHUS pa- tients, but its extremely high cost has caused the adjustment or withdrawal of the drug to be attempted. Nowadays, there are scarce of data to support these attitudes to be universally tried and more studies are necessary to select safely the adequate adjustment/discontinuation candidates.

\section{Acknowledgement}

No organizations have made substantive contributions to the research or the manuscript.

\section{Conflict of Interest Statement}

A.I.A.B. has received honoraria from Alexion and Takeda for expert meetings, advisory boards, and conferences. T.C.E. has received honoraria from Alexion for expert meetings and conferences. M.C.V. has received honoraria from Alexion and Takeda for expert meetings, conferences, and advisory boards. None of those aspects have influenced the writing of the manuscript.

\section{Funding Sources}

There are no funding sources.

\section{Author Contributions}

All the 3 authors have contributed to the writing of the manuscript.

\section{References}

1 Zhang K, Lu Y, Harley KT, Tran MH. Atypical hemolytic uremic syndrome: a brief review. Hematol Rep. 2017 Jun 1;9(2):7053.

2 Sheerin NS, Glover E. Haemolytic uremic syndrome: diagnosis and management. F1000Res. 2019 Sep 25;8:8.

3 Bayer G, von Tokarski F, Thoreau B, Bauvois A, Barbet C, Cloarec S, et al. Etiology and outcomes of thrombotic microangiopathies. Clin J Am Soc Nephrol. 2019 Apr 5;14(4):557-66.

4 Dixon BP, Gruppo RA. Atypical hemolytic uremic syndrome. Pediatr Clin North Am. 2018 Jun;65(3):509-25.

5 Goodship TH, Cook HT, Fakhouri F, Fervenza FC, Frémeaux-Bacchi V, Kavanagh D, et al. Atypical hemolytic uremic syndrome and C3 glomerulopathy: conclusions from a "Kidney Disease: Improving Global Outcomes" (KDIGO) controversies conference. Kidney Int. 2017 Mar;91(3):539-51.

6 Campistol JM, Arias M, Ariceta G, Blasco M, Espinosa L, Espinosa M, et al. An update for atypical haemolytic uraemic syndrome: diag- nosis and treatment. A consensus document. Nefrologia. 2015;35(5):421-47.

7 Jokiranta TS. HUS and atypical HUS. Blood. 2017 May 25;129(21):2847-56.

8 Noris M, Remuzzi G. Atypical hemolytic-uremic syndrome. N Engl J Med. 2009;361(17): 1676-87.

9 Constantinescu AR, Bitzan M, Weiss LS, Christen E, Kaplan BS, Cnaan A, et al. Nonenteropathic hemolytic uremic syndrome: causes and short-term course. Am J Kidney Dis. 2004;43(6):976-82.

10 Fremeaux-Bacchi V, Fakhouri F, Garnier A, Bienaimé F, Dragon-Durey MA, Ngo S, et al. Genetics and outcome of atypical hemolytic uremic syndrome: a nationwide French series comparing children and adults. Clin J Am Soc Nephrol. 2013;8(4):554-62.

11 Loirat C, Frémeaux-Bacchi V. Atypical hemolytic uremic syndrome. Orphanet J Rare Dis. 2011;6:60.

12 Licht C, Ardissino G, Ariceta G, Cohen D, Cole JA, Gasteyger C, et al. The global
aHUS registry: methodology and initial patient characteristics. BMC Nephrol. 2015; 16:207.

13 Karpman D, Loos S, Tati R, Arvidsson I. Haemolytic uraemic syndrome. J Intern Med. 2017 Feb;281(2):123-48

14 Berger BE. Atypical hemolytic uremic syndrome: a syndrome in need of clarity. Clin Kidney J. 2018 Jul 31;12(3):338-47.

15 Taylor CM, Chua C, Howie AJ, Risdon RA. Clinico-pathological findings in diarrhoeanegative haemolytic uraemic syndrome. Pediatr Nephrol. 2004 Apr;19(4):419-25.

16 Morigi M, Galbusera M, Gastoldi S, Locatelli M, Buelli S, Pezzotta A, et al. Alternative pathway activation of complement by Shiga toxin promotes exuberant $\mathrm{C} 3 \mathrm{a}$ formation that triggers microvascular thrombosis. J Immunol. 2011;187(1):172-80.

17 Scobel RR, Kaplan BS, Copelovitch L. New insights into the pathogenesis of Streptococcus pneumoniae-associated hemolytic uremic syndrome. Pediatr Nephrol. 2019 Sep 13. 
18 Loirat C, Fakhouri F, Ariceta G, Besbas N, Bitzan M, Bjerre A, et al. An international consensus approach to the management of atypical hemolytic uremic syndrome in children. Pediatr Nephrol. 2016;31(1):15-39.

19 Noris M, Caprioli J, Bresin E, Mossali C, Pianetti G, Gamba S, et al. Relative role of genetic complement abnormalities in sporadic and familial aHUS and their impact on clinical phenotype. Clin J Am Soc Nephrol. 2010 Oct;5(10):1844-59.

20 Caprioli J, Castelletti F, Bucchioni S, Bettinaglio P, Bresin E, Pianetti G, et al. Complement factor $\mathrm{H}$ mutations and gene polymorphisms in haemolytic uraemic syndrome: the C-257T, the A2089G and the G2881T polymorphisms are strongly associated with the disease. Hum Mol Genet. 2003;12(24): 3385-95.

21 Fremeaux-Bacchi V, Dragon-Durey MA, Blouin J, Vigneau C, Kuypers D, Boudailliez B, et al. Complement factor I: a susceptibility gene for atypical haemolytic uraemic syndrome. J Med Genet. 2004;41(6):e84.

22 Richards A, Kemp EJ, Liszewski MK, Goodship JA, Lampe AK, Decorte R, et al. Mutations in human complement regulator, membrane cofactor protein (CD46), predispose to development of familial hemolytic uremic syndrome. Proc Natl Acad Sci U S A. 2003; 100(22):12966-71.

23 Delvaeye M, Noris M, De Vriese A, Esmon CT, Esmon NL, Ferrell G, et al. Thrombomodulin mutations in atypical hemolyticuremic syndrome. N Engl J Med. 2009;361(4): 345-57.

24 Goicoechea de Jorge E, Harris CL, EsparzaGordillo J, Carreras L, Arranz EA, Garrido $\mathrm{CA}$, et al. Gain-of-function mutations in complement factor B are associated with atypical hemolytic uremic syndrome. Proc Natl Acad Sci U S A. 2007;104(1):240-5.

25 Frémeaux-Bacchi V, Miller EC, Liszewski MK, Strain L, Blouin J, Brown AL, et al. Mutations in complement $\mathrm{C} 3$ predispose to development of atypical hemolytic uremic syndrome. Blood. 2008;112(13):4948-52.

26 Dragon-Durey MA, Blanc C, Marliot F, Loirat C, Blouin J, Sautes-Fridman C, et al. The high frequency of complement factor $\mathrm{H}$ related CFHR1 gene deletion is restricted to specific subgroups of patients with atypical haemolytic uraemic syndrome. J Med Genet. 2009; 46(7):447-50.

27 Valoti E, Alberti M, Tortajada A, Garcia-Fernandez J, Gastoldi S, Besso L, et al. A novel atypical hemolytic uremic syndrome-associated hybrid CFHR1/CFH gene encoding a fusion protein that antagonizes factor $\mathrm{H}$-dependent complement regulation. J Am Soc Nephrol. 2015 Jan;26(1):209-19.

28 Goicoechea de Jorge E, Tortajada A, García SP, Gastoldi S, Merinero HM, García-Fernández J, et al. Factor $\mathrm{H}$ competitor generated by gene conversion events associates with atypical hemolytic uremic syndrome. J Am Soc Nephrol. 2018;29:240-9.
29 Bu F, Zhang Y, Wang K, Borsa NG, Jones MB, Taylor AO, et al. Genetic analysis of 400 patients refines understanding and implicates a new gene in atypical hemolytic uremic syndrome. Am Soc Nephrol. 2018 Dec;29(12):2809-19.

30 Azukaitis K, Simkova E, Majid MA, Galiano M, Benz K, Amann K, et al. The phenotypic spectrum of nephropathies associated with mutations in diacylglycerol kinase. J Am Soc Nephrol. 2017;28:3066-75.

31 Lemaire M, Frémeaux Bacchi V, Schaefer F, Choi M, Tang WH, Le Quintrec M, et al. Recessive mutations in DGKE cause atypical hemolitic syndrome. Nat Genet. 2013;45(5): 531-6.

32 Fujisawa M, Kato H, Yoshida Y, Usui T, Takata $\mathrm{M}$, Fujimoto $\mathrm{M}$, et al. Clinical characteristics and genetic backgrounds of Japanese patients with atypical hemolytic uremic syndrome. Clin Exp Nephrol. 2018;22:1088-9.

33 Maga T, Nishimura C, Weaver A, Frees KL, Smith RJH. Mutations in alternative pathway complement proteins in American patients with atypical hemolytic uremic syndrome. Hum Mutat. 2010;31:E-1445-60.

34 Nishimura J, Yamamoto M, Hayashi S, Ohyashiki K, Ando K, Brodsky AL, et al. Genetics variants in $\mathrm{C} 5$ and poor response to eculizumab. N Engl J Med. 2014;370:632-9.

35 Esparza Gordillo J, Goicoechea de Jorge E, Buil A, Berges LC, López-Trascasa M, Sánchez-Corral P, et al. Predisposition to atypical hemolytic uremyc syndrome involves the concurrence of different susceptibility alleles in the regulators of complement activation gene cluster in 1q32. Hum Mol Genet. 2005.14;703-12.

36 Bresin E, Rurali E, Caprioli J, Sanchez-Corral P, Fremeaux-Bacchi, V, de Cordoba SR, et al. Combined complement gene mutations in atypical hemolytic uremic syndrome influence clinical phenotipe. J Am Soc Nephrol. 2013;24:475-86

37 Sallee M, Ismail K, Fakhouri F, Vacher-Coponat $\mathrm{H}$, Moussi-Francés J, Frémaux-Bacchi $\mathrm{V}$, et al. Thrombocytopenia is not mandatory to diagnose haemolytic and uremic syndrome. BMC Nephrol. 2013 Jan 8;14:3.

38 Belingheri M, Possenti I, Tel F, Paglialonga F, Testa S, Salardi S, et al. Cryptic activity of atypical hemolytic uremic syndrome and eculizumab treatment. Pediatrics. 2014;133(6):1769-71.

39 Avila A, Vizcaíno B, Molina P, Gavela E, Perez-Ebri M, Pallardó LM. Remission of aHUS neurological damage with eculizumab. Clin Kidney J. 2015 Apr;8(2):232-6.

40 Weitz IC. Thrombotic microangiopathy in cancer. Semin Thromb Hemost. 2019;45(4): $348-53$.

41 Izzedine H, Perazella MA. Thrombotic microangiopathy, cancer, and cancer drugs. Am J Kidney Dis. 2015;66(5):857-68.

42 Huerta A, Arjona A, Portoles J, Lopez-Sanchez P, Rabasco C, Espinosa M, et al. A retrospective study of pregnancy-associated atypical hemolytic uremic syndrome. Kidney Int. 2018;93(2):450-9.
43 Jodele S, Laskin BL, Dandoy CE, Myers KC, El-Bietar J, Davies SM, et al. A new paradigm: diagnosis and management of HSCT-associated thrombotic microangiopathy as multisystem endothelial injury. Blood Rev. 2015; 29(3):191-204.

44 Giannakopoulos B, Krilis SA. The pathogenesis of the antiphospholipid syndrome. N Engl J Med. 2013;368(11):1033-44.

45 Devresse A, Aydin S, Le Quintrec M, Demoulin N, Stordeur P, Lambert C, et al. Complement activation and effect of eculizumab in scleroderma renal crisis. Medicine. 2016; 95(30):e4459.

46 Gervasoni C, Ridolfo AL, Vaccarezza M, Parravicini $\mathrm{C}$, Vago L, Adorni F, et al. Thrombotic microangiopathy in patients with acquired immunodeficiency syndrome before and during the era of introduction of highly active antiretroviral therapy. Clin Infect Dis. 2002;35(12):1534-40.

47 Murer L, Zacchello G, Bianchi D, Dall'Amico R, Montini G, Andreetta D, et al. Thrombotic microangiopathy associated with parvovirus B 19 infection after renal transplantation. J Am Soc Nephrol. 2000;11(6): 1132-7.

48 Takatsuka H, Wakae T, Mori A, Okada M, Fujimori Y, Takemoto Y, et al. Endothelial damage caused by cytomegalovirus and human herpesvirus-6. Bone Marrow Transpl. 2003;31(6):475-9

49 Bitzan M, Zieg J. Influenza-associated thrombotic microangiopathies. Pediatr Nephrol. 2018;33(11):2009-25.

50 Cavero T, Rabasco C, López A, Román E, Ávila A, Sevillano A, et al. Eculizumab in secondary atypical haemolytic uraemic syndrome. Nephrol Dial Transpl. 2017;32(3):466-74.

51 Cavero T, Arjona E, Soto K, Caravaca-Fontán F, Rabasco C, Bravo L, et al. Severe and malignant hypertension are common in primary hemolytic uremic syndrome. Kidney Int. 2019;96(4):995-1004.

52 Fakhouri F, Roumenina L, Provot F, Sallée M, Caillard S, Couzi L, et al. Pregnancy-associated hemolytic uremic syndrome revisited in the era of complement gene mutations. J Am Soc Nephrol. 2010;21(5):859-67.

53 Bruel A, Kavanagh D, Noris M, Delmas Y, Wong EKS, Bresin E, et al. Hemolytic uremic syndrome in pregnancy and postpartum. Clin J Am Soc Nephrol. 2017;12(8): 1237-47.

54 Lechner K, Obermeier HL. Cancer-related microangiopathic hemolytic anemia: clinical and laboratory features in 168 reported cases. Medicine. 2012;91(4): 195-205

55 Banerjee R, Hersh AL, Newland J, Beekmann SE, Polgreen PM, Bender J, et al. Streptococcus pneumoniae-associated hemolytic uremic syndrome among children in North America. Pediatr Infect Dis J. 2011;30(9): 736-9.

56 Cornec-Le Gall E, Delmas Y, De Parscau L, Doucet L, Ogier H, Benoist JF, et al. Adultonset eculizumab-resistant hemolytic uremic syndrome associated with cobalamin C deficiency. Am J Kidney Dis. 2014;63(1): 119-23. 
57 Michon B, Moghrabi A, Winikoff R, Barrette S, Bernstein ML, Champagne J, et al. Complications of apheresis in children. Transfusion. 2007;47(10):1837-42.

58 Khandelwal P, Thomas CC, Rathi BS, Hari P, Tiwari AN, Sinha A, et al. Membrane-filtration based plasma exchanges for atypical hemolytic uremic syndrome: audit of efficacy and safety. J Clin Apher. 2019 Oct;34(5):55562.

59 Saland JM, Shneider BL, Bromberg JS, Shi PA, Ward SC, Magid MS, et al. Successful split liver-kidney transplant for factor $\mathrm{H}$ associated hemolytic uremic syndrome. Clin J Am Soc Nephrol. 2009;4(1):201-6.

60 Cheong HI. Thrombotic microangiopathy: can liver-kidney transplantation cure aHUS? Nat Rev Nephrol. 2009;5(10):556-7.

61 Coppo R, Bonaudo R, Peruzzi RL, Amore A, Brunati A, Romagnoli R, et al. Liver transplantation for aHUS: still needed in the eculizumab era? Pediatr Nephrol. 2016;31(5):75968.

62 Legendre CM, Licht C, Muus P, Greenbaum LA, Babu S, Bedrosian C, et al. Terminal complement inhibitor eculizumab in atypical hemolytic-uremic syndrome. N Engl J Med. 2013;368(23): 2169-81.

63 Licht C, Greenbaum LA, Muus P, Babu S, Bedrosian CL, Cohen DJ, et al. Efficacy and safety of eculizumab in atypical hemolytic uremic syndrome from 2-year extensions of phase 2 studies. Kidney Int. 2015;87:106173.

64 Greenbaum LA, Fila M, Ardissino G, AlAkash SI, Evans J, Henning P, et al. Eculizum$a b$ is a safe and effective treatment in pediatric patients with atypical hemolytic uremic syndrome. Kidney Int. 2016;89:701-11.

65 Cao M, Leite BN, Ferreiro T, Calvo M, Fernández C, Alonso A, et al. Eculizumab modifies outcomes in adults with atypical hemolytic uremic syndrome with acute kidney injury. Am J Neph. 2018;48:225-33.

66 Walle JV, Delmas Y, Ardissino G, Wang J, Kincaid JF, Haller H. Improved renal recovery in patients with atypical hemolytic uremic syndrome following rapid initiation of eculizumab treatment. J Nephrol. 2017;30(1):12734.

67 Galbusera M, Noris M, Gastoldi S, Bresin E, Mele C, Breno M, et al. An ex vivo test of complement activation on endothelium for individualized eculizumab therapy in hemolytic uremic syndrome. Am J Kidney Dis. 2019 Jul; 74(1):56-72.

68 Kim JJ, Waller SC, Reid CJ. Eculizumab in atypical haemolytic-uraemic syndrome allows cessation of plasma exchange and dialysis. Clin Kidney J. 2012 Feb;5(1):34-6.

69 Povey H, Vundru R, Junglee N, Jibani M. Renal recovery with eculizumab in atypical hemolytic uremic syndrome following prolonged dialysis. Clin Nephrol. 2014;82:32631.

70 Emirova K, Volokhina E, Tolstova E, van den Heuvel B. Recovery of renal function after long-term dialysis and resolution of cardiomyopathy in a patient with aHUS receiving eculizumab. BMJ Case Rep. 2016 Feb 15;2016: bcr2015213928.

71 Valente RA, Rodriguez GEG, Marcote YG, Díaz MF, Mosquera VB, García DN, et al. Discontinuation of peritoneal dialysis after late initiation of eculizumab in a case of familial atypical hemolytic-uremic syndrome: a case report. Case Rep Nephrol Dial. 2017;7: $18-25$.

72 Haskin O, Falush Y, Davidovits M. Is eculizumab indicated in patients with atypical hemolytic uremic syndrome already on prolonged dialysis? A case report and review of the literature. Pediatr Nephrol. 2019 Dec; 34(12):2601-4

73 Raina R, Grewal MK, Radhakrishnan Y, Tatineni V, DeCoy M, Burke LLG, et al. Optimal management of atypical hemolytic uremic disease: challenges and solutions. Int J Nephrol Renovasc Dis. 2019 Sep 4;12:183204.

74 Ardissino G, Testa S, Possenti I, Tel F, Paglialonga F, Salardi S, et al. Discontinuation of eculizumab maintenance treatment for atypical hemolytic uremic syndrome: a report of 10 cases. Am J Kidney Dis. 2014;64(4): 633-7.

75 Menne J, Delmas Y, Fakhouri F, Licht C, Lommelé A, Minetti EE, et al. Outcomes in patients with atypical hemolytic uremic syndrome treated with eculizumab in a longterm observational study. BMC Nephrol. 2019 Apr 10;20(1):125.

76 Macia M, de Alvaro Moreno F, Dutt T, Fehrman I, Hadaya K, Gasteyger C, et al. Current evidence on the discontinuation of eculizumab in patients with atypical hemolytic uremic syndrome. Clin Kidney J. 2017; 10(3):310-9.

77 Wijnsma KL, Duineveld C, Volokhina EB, van den Heuvel LP, van de Kar NCAJ, Wetzels JFM. Safety and effectiveness of restrictive eculizumab treatment in atypical haemolytic uremic syndrome. Nephrol Dial Transpl. 2018;33(4): 635-45.

78 Cugno M, Gualtierotti R, Possenti I, Testa S, Tel F, Griffini G, et al. Complement functional tests for monitoring eculizumab treatment in patients with atypical hemolytic uremic syndrome. J Thromb Haemost. 2014 Sep; 12(9):1440-8.

79 Noris M, Galbusera M, Gastoldi S, Macor P, Banterla F, Bresin E, et al. Dynamics of complement activation in aHUS and how to monitor eculizumab therapy. Blood. 2014 Sep; 124(11):1715-26.

80 Gatault P, Brachet G, Ternant D. Therapeutic drug monitoring of eculizumab: rationale for an individualized dosing schedule. MAbs. 2015;7(6):1205-11.

81 Volokhina EB, van de Kar NC, Bergseth G, van der Velden TJAM, Westra D, Wetzels JFM, et al. Sensitive, reliable and easy-performed laboratory monitoring of eculizumab therapy in atypical hemolytic uremic syn- drome. Clin Immunol. 2015 Oct;160(2):23743.

82 Peffault de Latour R, Fremeaux-Bacchi V, Porcher R, Xhaard A, Rosain J, Castaneda DC, et al. Assessing complement blockade in patients with paroxysmal nocturnal hemoglobinuria receiving eculizumab. Blood. 2015 Jan 29;125(5):775-83.

83 Noris M, Remuzzi G. Thrombotic microangiopathy after kidney transplantation. Am J Transpl. 2010;10:1517-23.

84 Le Quintrec M, Lionet A, Kamar N, Karras A, Barbier S, Buchler M, et al. Complement mutation-associated de novo thrombotic microangiopathy following kidney transplantation. Am J Transpl. 2008;8:1694701.

85 Caires RA, Marques ID, Repizo LP, Sato VA, Carmo LP, Machado DJ, et al. De novo thrombotic microangiopathy after kidney transplantation: Clinical features, treatment, and long-term patient and graft survival. Transpl Proc. 2012;44:2388-90.

86 Sacks SH, Zhou W. The role of complement in the early immune response to transplantation. Nat Rev Immunol. 2012;12:431-42.

87 Java A, Edwards A, Rossi A, Pandey R, Gaut J, De los Santos R, et al. Cytomegalovirus-induced thrombotic microangiopathy after renal transplant successfully treated with eculizumab: case report and review of the literature. Transpl Int. 2015;28:1121-5.

88 Renner B, Klawitter J, Goldberg R, McCullough JW, Ferreira VP, Cooper JE, et al. Cyclosporine induces endothelial cell release of complement-activating microparticles. J Am Soc Nephrol. 2013;24:1849-62.

89 Nava F, Cappelli G, Mori G, Granito M, Magnoni G, Botta C, et al. Everolimus, cyclosporine, and thrombotic microangiopathy: clinical role and preventive tools in renal transplantation. Transpl Proc. 2014;46: 2263-8.

90 Zuber J, Frimat M, Caillard S, Kamar N, Gatault P, Petitprez F, et al. Use of highly individualized complement blockade has revolutionized clinical outcomes after kidney transplantation and renal epidemiology of atypical hemolytic uremic syndrome. J Am Soc Nephrol. 2019;30(12):2449-63.

91 Le Quintrec M, Zuber J, Moulin B, Kamar $\mathrm{N}$, Jablonski M, Lionet A, et al. Complement genes strongly predict recurrence and graft outcome in adult renal transplant recipients with atypical hemolytic uremic syndrome. Am J Transpl. 2013;13(3):66375 .

92 Zimmerhackl LB, Lesbas N, Jungraithmayr T, van de Kar N, Karch H, Karpman D, et al. Epidemiology, clinical presentation and pathophysiology of atypical and recurrent hemolytic uremic syndrome. Semin Thromb $\mathrm{He}-$ most. 2006;32(2):113-20.

93 Rodriguez E, Barrios C, Soler MJ. Should eculizumab be discontinued in patients with atypical hemolytic uremic syndrome? Clin Kidney J. 2017;10(3):320-2. 
94 Fakhouri F, Fila M, Provôt F, Delmas Y, Barbet $\mathrm{C}$, Châtelet $\mathrm{V}$, et al. Pathogenic variants in complement genes and risk of atypical hemolytic uremic syndrome relapse after eculizumab discontinuation. Clin J Am Soc Nephrol. 2017;12(1):50-9.

95 van den Brand JA, Verhave JC, Adang EM, Wetzels JFM. Cost-effectiveness of eculizumab treatment after kidney transplantation in patients with atypical hemolytic uremic syndrome. Nephrol Dial Transpl. 2017;32(Suppl 1):i115-22.
96 Duineveld C, Verhave JC, Berger SP, van de Kar NCAJ, Wetzels JFM. Living donor kidney transplantation in atypical hemolytic uremic syndrome: a case series. Am J Kidney Dis. 2017;70(6):770-6.

97 Noris M, Ruggenenti P, Remuzzi G. Kidney transplantation in patients with atypical hemolytic uremic syndrome: a therapeutic dilemma (or not)? Am J Kidney Dis. 2017;70(6): 754-7.
98 Fayek S, Allan S, Martinez E, Pan G, Dao A, Rofaiel G. Atypical hemolytic uremic syndrome after kidney transplantation: lessons learned from the good, the bad, and the ugly. A case series with literature review. Transplant Proc. 2020;52:146-52.

99 Zipfel PF, Wiech T, Rudnick R, Afonso S, Person F, Skerka C. Complement inhibitors in clinical trials for glomerular diseases. Front Immunol. 2019 Sep 27;10:2166. 